\title{
A spindle cell variant of diffuse large B-cell lymphoma possesses genotypic and phenotypic markers characteristic of a germinal center B-cell origin
}

\author{
Antonino Carbone ${ }^{1}$, Annunziata Gloghini², Massimo Libra ${ }^{3}$, Daniela Gasparotto ${ }^{4}$, \\ Patrick M Navolanic ${ }^{3}$, Michele Spina ${ }^{5}$ and Umberto Tirelli ${ }^{5}$ \\ ${ }^{1}$ Department of Pathology, Istituto Nazionale Tumori, Milano, Italy; ${ }^{2}$ Diagnostic Immunohistochemistry and \\ Molecular Pathology Unit, Centro di Riferimento Oncologico, Istituto Nazionale Tumori, Aviano, Italy; \\ ${ }^{3}$ Department of Biomedical Sciences, University of Catania, Catania, Italy; ${ }^{4}$ Divisions of Experimental \\ Oncology 1, Centro di Riferimento Oncologico, Istituto Nazionale Tumori, Aviano, Italy and ${ }^{5}$ Lymphoma Unit \\ and Medical Oncology A, Centro di Riferimento Oncologico, Istituto Nazionale Tumori, Aviano, Italy
}

\begin{abstract}
Lymphoma with prominent spindle cell features, the so-called spindle cell lymphoma, is an unusual morphological variant of diffuse large B-cell lymphoma. Five new cases of spindle cell lymphoma have been analyzed by a multiparameter approach in order to clarify its clinical and biological features. All patients presented advanced stage disease with extranodal involvement. Vagina was the most common extranodal site. All patients received chemotherapy and are alive in complete remission. Morphologically, all five cases exhibited proliferation of spindle cells with a vaguely storiform pattern highly suggestive of spindle cell neoplasms of nonlymphoid origin. In contrast, the results of immunohistochemical analysis indicated that all five cases were hematolymphoid neoplasms of the B-cell lineage. These lymphomas consisted of a B-cell clonal population which exhibited somatic immunoglobulin and BCL-6 mutations as well as BCL-6 protein expression. The neoplastic spindle cells therefore closely resemble B cells residing in the germinal center. The absence of MUM1 expression in neoplastic spindle cells suggested that neoplastic spindle cells may be related to the early phases of intragerminal center maturation of B cells. The germinal center phenotype, with restricted expression of BCL-6, was associated with the presence of a primary extranodal origin, normal lactate dehydrogenase levels, and good response to treatment.
\end{abstract}

Modern Pathology (2006) 19, 299-306. doi:10.1038/modpathol.3800540; published online 6 January 2006

Keywords: diffuse large B-cell lymphoma; spindle cell; lymphoma

Lymphoma with prominent spindle cell features, also termed spindle cell lymphoma, is an unusual morphological variant of diffuse large B-cell lymphoma. ${ }^{1}$ However, according to previous reports, spindle cell lymphoma phenotypically can be of Tand B-cell type ${ }^{1-4}$ and can express actin. ${ }^{2,4}$ Lymphoma cells may assume a spindle configuration when they infiltrate bone and soft tissues. ${ }^{5,6}$ Lymphoma cells are also occasionally spindled in the absence of stromal influence, presumably resulting from cytoskeletal aberrations., ${ }^{1,2,7}$ The clinical behavior and prognosis of spindle cell lymphoma is not well

Correspondence: Dr A Carbone, MD, Department of Pathology, Istituto Nazionale Tumori, via Venezian 1, Milano I-20133, Italy. E-mail: antonino.carbone@istitutotumori.mi.it

Received 22 September 2005; revised 15 November 2005; accepted 16 November 2005; published online 6 January 2006 understood as is reflected by the scarcity of available staging and follow-up data. ${ }^{8}$

Pitfalls in the histologic diagnosis have been reported by previous studies focusing on the differential diagnosis of spindle cell lymphoma. Spindle cell lymphoma has a similar morphology to other neoplasms with spindle cell features, including soft tissue sarcoma, spindle cell carcinoma, spindle cell melanoma, and dendritic cell tumor. Appropriate immunohistochemical analysis is a useful diagnostic tool to distinguish spindle cell lymphoma from morphologically similar neoplasms arising from nonlymphoid tissue. ${ }^{1-3,7-10}$

The origin of the spindled cells in diffuse large B-cell lymphoma remains unclear. Morphological features suggest that cases of cutaneous spindle cell lymphoma originate from germinal center B cells. ${ }^{9}$ 
However, histogenetic analysis of spindle cell lymphoma cases has not previously been reported to address this possibility. Well-defined histogenetic markers of B-cell lymphoma currently include mutations of immunoglobulin and $B C L-6$ genes and expression of CD10, BCL-6, MUM1, and CD138/syndecan-1 antigens. ${ }^{11-19}$ These markers are useful indicators of the origin and differentiation stage of B-cell lymphoma because each are retained upon neoplastic transformation.

In the present study, a combined clinicopathologic, immunophenotypic, and immunogenotypic analysis was performed for a series of five new cases of diffuse large B-cell lymphoma with prominent spindle cell features in order to clarify its clinical and biological features. These studies included analysis of immunoglobulin and BCL-6 gene mutation and expression of phenotypic markers of histogenesis to characterize the origin of spindle cell lymphoma. The results of this study indicate that spindle cell variant of diffuse large B-cell lymphoma exhibits phenotypic and genotypic markers of germinal center B cells and is associated, from a clinical point of view, with extranodal disease, advanced stage at presentation, and a good response to treatment.

\section{Patients, materials, and methods}

\section{Clinical Staging}

All patients were evaluated for history and physical examination, including height, weight and WHO performance status; measurement of all involved palpable lesions; complete blood cell count; blood chemistry; chest radiography, computer tomography of the thorax and abdomen; bone marrow aspiration and biopsy; electrocardiogram and left ventricular ejection fraction evaluation; gastroscopy when indicated. Ann Arbor staging system was applied.

\section{Neoplastic Samples}

Two cases were seen as personal pathologic consultation to one us (AC). Three cases of spindle cell lymphoma patients belonged to a single Institution series of systemic diffuse large B-cell lymphoma. All cases were reviewed (by AC and AG) for the purpose of this study and were classified according to 'Atlas of Tumor Pathology' (Armed Forces Institute of Pathology, 1994) ${ }^{1}$ and to the 2001 World Health Classification of Tumours of Haematopoietic and Lymphoid Tissues. ${ }^{20}$

Tissues were fixed in Bouin solution or neutral buffered formalin. In three cases, a portion of unfixed tissue was snap frozen in liquid nitrogen and stored at $-80^{\circ} \mathrm{C}$.

Informed written consent was obtained from the patients, and tissue collection was approved by Institutional Review Board.

\section{Immunohistological Studies}

All five cases included in the study had been immunophenotyped as previously described. ${ }^{21}$

In an attempt to refine the histogenesis of spindle cell lymphomas, we have specifically analyzed the expression pattern of CD10, BCL-6, MUM1, and syn-1. CD10 staining was detected by the 56C6 monoclonal antibody (Novocastra Laboratories Ltd, Newcastle-upon-Tyne, UK). The BCL-6 protein was detected by the PG-B6 monoclonal antibody (Dakopatts A/S, Glostrup, Denmark). The expression of MUM1 was investigated with an affinity-purified polyclonal goat antibody (ICSAT/M-17) specific for the MUM1 protein (Santa Cruz Biotechnology Inc., Santa Cruz, CA, USA). The M-17 antibody reacts with MUM1 of mouse, rat and human origins, although it does not crossreact with other members of the IRF family proteins. Syn-1 expression was assessed using the B-B4 monoclonal antibody (Serotec, Oxford, UK).

All antigens were tested on paraffin-embedded tissue sections. For CD10, BCL-6, and MUM1 assessment, paraffin-embedded sections were treated in a microwave oven at $250 \mathrm{~W}$ for $30 \mathrm{~min}$ in EGTA solution (1 mM pH 8) (for MUM1 and BCL-6) or citrate buffer ( $\mathrm{pH}$ 6) (for CD10). Immunostaining for MUM1, BCL-6, and CD10 was performed on an automated immunostainer (Nexes, Ventana Medical Systems, Inc, Tucson, AZ, USA) according to a modified version of the company's protocols. Immunostaining for syn-1 was performed by using the APAAP method. Only definite and unambiguous staining on unequivocal malignant cells was accepted as positive.

\section{Molecular Analysis of Clonality}

Genomic DNA was isolated from tumor biopsy specimens by using the Nucleospin Tissue system (Macherey-Nagel GmbH \& Co., Düren, Germany) according to the manufacturer's protocol with minor modification.

Presence of monoclonal B-cell expansion was assessed by polymerase chain reaction amplification of the immunoglobulin heavy chain $(\mathrm{H}) \mathrm{V}-\mathrm{D}-\mathrm{J}$ gene rearrangement from tumor biopsy DNA. The upstream primers were complementary to the framework regions (FR1, FR2, or FR3) whereas the downstream primers were complementary to $\mathrm{JH}$ genes. ${ }^{22}$ DNA samples were assayed in duplicate. Polymerase chain reaction products were analyzed by agarose gel electrophoresis and ethidium bromide staining. Samples showing a monoclonal pattern were purified by the Montage DNA gel extraction kit (Millipore) and sequenced according to the BigDye Terminator Kit v.3.1 (PE Applied Biosystems) on the ABI PRISM 3100 genetic analyzer. The most similar $\mathrm{VH}, \mathrm{DH}$, and $\mathrm{JH}$ immunoglobulin germline genes were identified by the IMGT/V-QUEST program (IMGT, the 
international ImMunoGeneTics information system ${ }^{\circledR}$ http://imgt.cines.fr).

T-cell receptor gamma chain gene rearrangements was carried out by polymerase chain reaction according to standard protocols, using previously reported primer sequences. ${ }^{22}$

\section{Molecular Analysis of $\mathbf{t}(14 ; 18)$}

The $\mathrm{t}(14 ; 18)$ was assessed by polymerase chain reaction by using a BLC2/JH translocation assay kit (InVivoScribe Technologies, San Diego, CA, USA) according to the manufacturer's protocol. Positive and negative control DNAs were included in the kit. In addition, DNAs obtained from two follicular lymphomas with known $\mathrm{t}(14 ; 18)$ translocation involving, respectively, the major breakpoint region or the minor cluster region were used as supplementary positive controls.

\section{Molecular Analysis of BCL-6 Mutations}

The $5^{\prime}$ noncoding region of $B C L-6$ was amplified by the oligonucleotide primers BCL6-10F: $5^{\prime}$-CTC TTG CCA AAT GCT TTG-3' and BCL6-12R: 5'-CAC GAT ACT TCA TCT CAT C-3' for the analysis of somatic mutations. Size of $B C L-6$ polymerase chain reaction products was $739 \mathrm{bp}$. Both strands of the polymerase chain reaction product were sequenced and compared to the wild-type BCL- 6 sequence (GenBank accession number AY189709). The mutation frequency for nucleotides occurring in the context of an RGYW/WRCY motif was compared to the expected mutation frequency by the goodness-of-fit $\chi^{2}$-test. ${ }^{23}$

\section{Analysis of Viral Infection}

The samples from all the cases included in the study were subjected to determination of tumor infection by Kaposi's sarcoma-associated herpesvirus and Epstein-Barr virus as previously described. ${ }^{24}$

\section{Results}

\section{Case History}

Major clinical features are summarized in Table 1.

All patients presented good general conditions (performance status 0-2) and without systemic symptoms. Advanced stage disease (stage IV) occurred in four patients. Tumor localization included lymph node involvement (three patients) and consistent extranodal disease. Vagina was the most common extranodal site.

Abnormal lactate dehydrogenase serum level was detected in one patient (Case 4), while hypoalbuminemia was not detected in all patients. All patients were HCV seronegative except patient 1.

All patients received six course of full-dose chemotherapy followed by radiotherapy in two patients. All patients are alive and in first complete remission lasting $20+, 7+, 4+, 6+$, and $57+$ months, respectively.

\section{Histopathologic Analysis of the Spindle Cell Lymphomas}

Histopathological analysis was carried out in vaginal tumor biopsies from two patients (Cases 1 and 2) in whom the disease was restricted to extranodal sites, whereas the analysis was carried out in lymph node biopsies from other two patients (Cases 4 and 5) in whom the disease was located in both nodal and extranodal sites. In the remaining case (Case 3) the histopathological analysis was applied to an intraparotideal lymph node and the contiguous salivary gland which were involved by the lymphoma.

The five cases had several similar histopathologic features. All cases showed a proliferation of compact spindle and round cells. The cells were arranged in irregular, short fascicles displaying a vague storiform pattern (Figure 1). A storiform or

Table 1 Main clinical features of patients with spindle cell lymphomas

\begin{tabular}{|c|c|c|c|c|c|}
\hline & Case 1 & Case 2 & Case 3 & Case 4 & Case 5 \\
\hline Age/sex & $21 / \mathrm{F}$ & $67 / \mathrm{F}$ & 48/M & $70 / \mathrm{F}$ & $71 / \mathrm{F}$ \\
\hline PS WHO & 0 & 0 & 0 & 2 & 1 \\
\hline Stage & IV & I & IV & IV & IV \\
\hline B-symptoms & No & No & No & No & No \\
\hline Bulky disease & Yes & No & No & Yes & Yes \\
\hline $\begin{array}{l}\text { Extranodal involvement } \\
\text { (sites) }\end{array}$ & Vagina, uterus & Vagina & Salivary gland, liver & Liver & Soft tissue, skin \\
\hline Lymph node involvement & No & No & Yes & Yes & Yes \\
\hline Bone marrow involvement & No & No & No & No & No \\
\hline LDH serum level & 288 (normal) & 252 (normal) & 270 (normal) & 675 (elevated) & 262 (normal) \\
\hline Albuminemia & 4.0 & 4.0 & 4.2 & 4.5 & 4 \\
\hline Therapy (no. of cycle) & $\begin{array}{l}\text { Intensified-CHOP } \\
(6)+\mathrm{RT}\end{array}$ & $\begin{array}{l}\text { Rituximab+CHOP } \\
\text { (4) }\end{array}$ & $\begin{array}{l}\text { Rituximab+VACOP-B } \\
\text { (12) }\end{array}$ & Rituximab+CHOP (6) & CIEP (6)+RT \\
\hline Outcome & Alive (CR, 20+mo) & Alive (CR, 7+mo) & Alive (CR, 4+mo) & Alive (CR, 6+mo) & Alive (CR, 57+mo) \\
\hline
\end{tabular}

$\mathrm{F}=$ female; $\mathrm{M}=$ male; $\mathrm{PS}=$ performance status; $\mathrm{LDH}=$ lactate dehydrogenase; $\mathrm{CHOP}=$ cyclophosphamide, doxorubicin, vincristine, prednisone; $\mathrm{RT}=$ radiotherapy; VACOP-B = etoposide, doxorubicin, cyclophosphamide, vincristine, prednisone, bleomycin; CIEP = cyclophosphamide, idarubicin, epirubicin, prednisone; $\mathrm{CR}=$ complete remission; $\mathrm{mo}=$ months. 

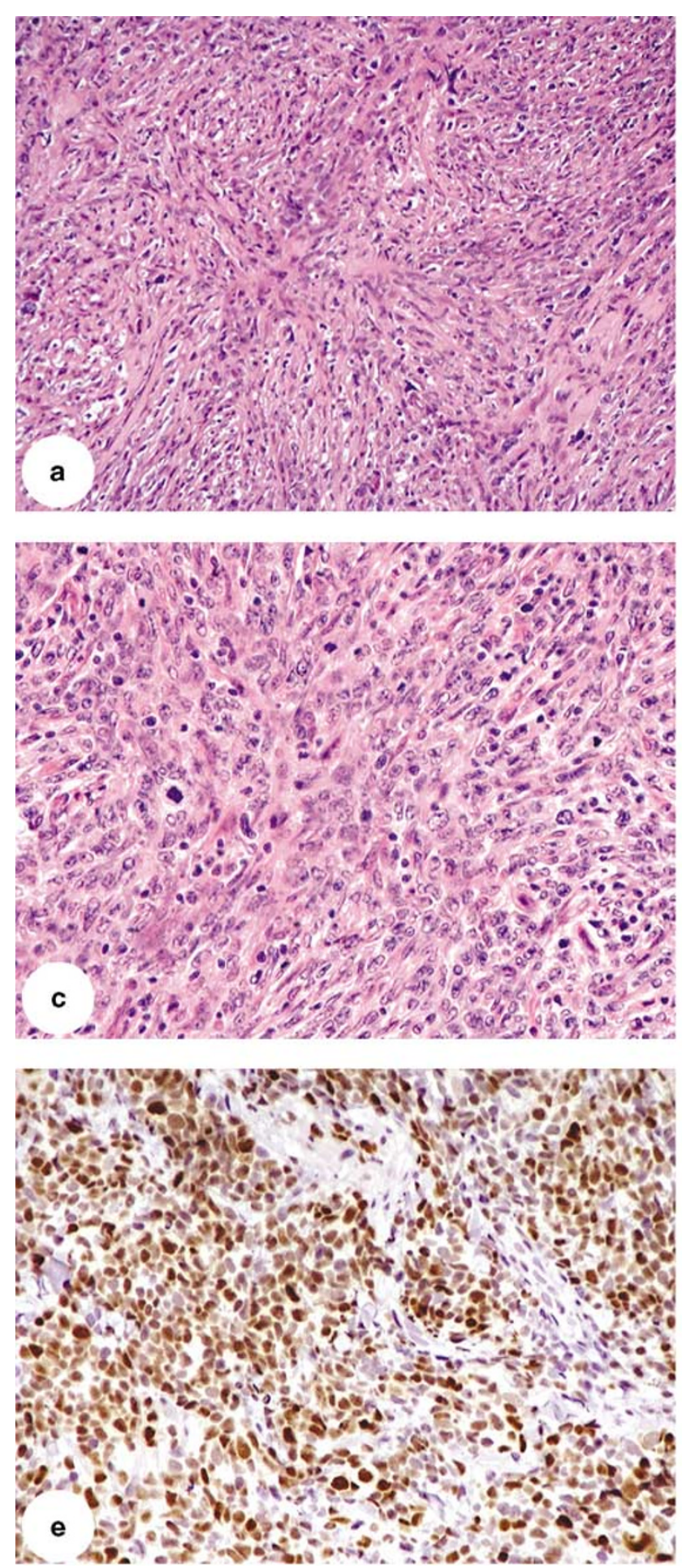
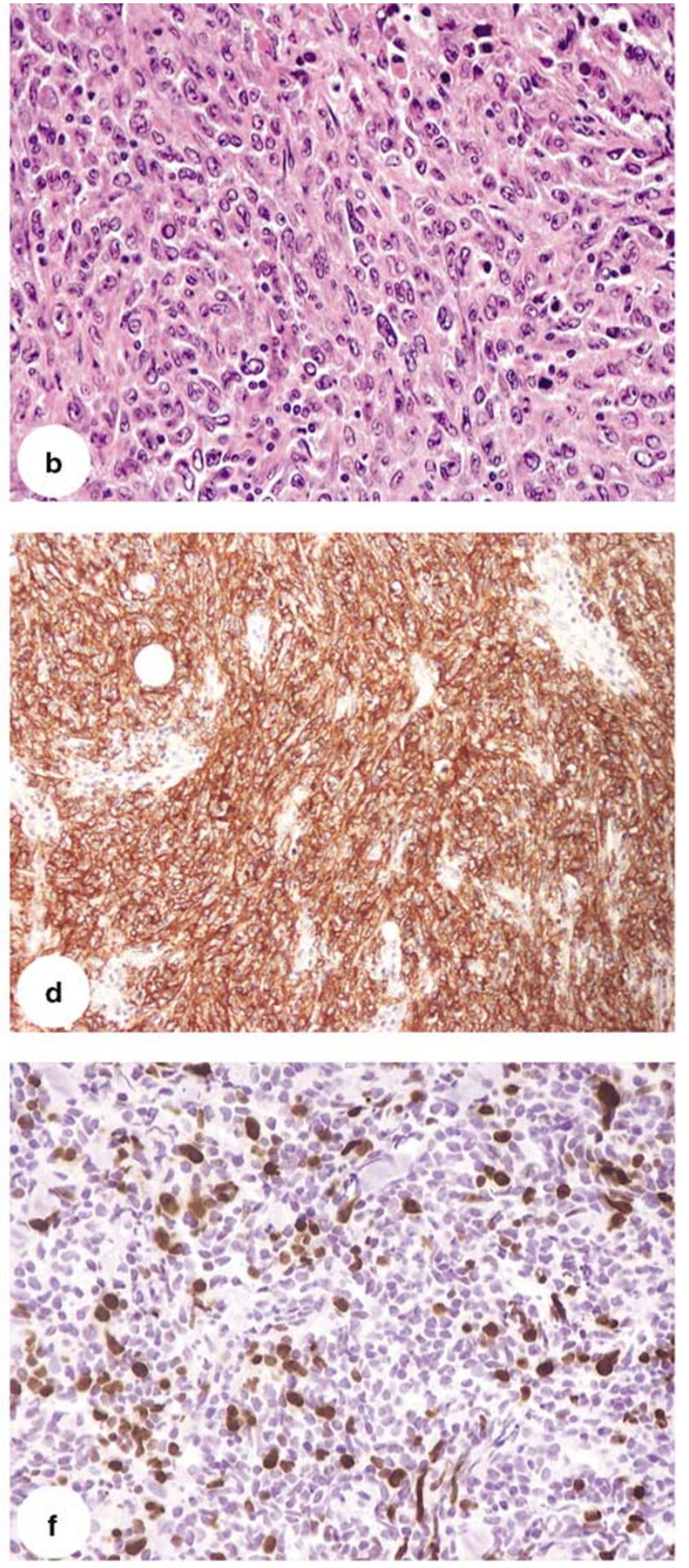

Figure 1 Spindle cell lymphomas exhibit prominent proliferation of spindle and round cells, express phenotypic markers characteristic of a germinal center B-cell origin and have a high proliferation index. (a) Case 1: neoplastic spindle cells are arranged in short fascicles, producing a vague storiform pattern. (b) Case 5: neoplastic spindle cells contain oval, elongated or folded vesicular nuclei and one to several small nucleoli. The cytoplasm is moderate in amount with distinct cell borders. (c) Case 4: the lymphoma cells assume a spindly configuration and possess elongated nuclei. (d) The neoplastic spindle cells in Case 4 exhibit a strong immunoreactivity with anti-CD20, confirming a B-cell lineage. (e) Almost all of the spindle lymphoma cells in Case 4 display strong nuclear immunoreactivity with BCL-6 indicating that neoplastic spindle cells may be related to B cells residing in the germinal center. (f) MIB1 antibody outlines elongated nuclei of proliferating cells in Case 4. Paraffin-embedded tissue sections (a-c) hematoxylin-eosin stain, (d-f) immunoperoxidase stain, hematoxylin counterstain. Original magnification $\times 200(\mathbf{a}$ and d), $\times 400(\mathbf{b}, \mathbf{c}, \mathbf{e}$ and f). 
fascicular pattern was present in areas representing $20-25$ to $60 \%$ of the infiltrate. The prominent population consisted of cells with elongated or spindle-shaped nuclei and one to several small nucleoli (Figure 1). The cytoplasm was pale with indistinct cell borders. In all cases there were thickened collagen bundles interposed between the tumor cells. However, areas more diagnostic for lymphoma were consistently found.

\section{Immunophenotypic Analysis}

Immunohistologic analysis revealed that all five cases were positive for CD45 and expressed a B-cell phenotype (Table 2 and Figure 1). Conversely, tumor cells from all five cases were negative for vimentin, smooth muscle actin, S100, CD31, CD34, and cheratin (mix of MNF116 and CAM 5.2).

The expression pattern of the histogenetic markers, was rather homogeneous. In fact, lymphomatous cells of all cases were positive for BCL-6 (Figure 1 ), but negative for CD10, MUM1, and syn-1. The proliferation index as assessed by MIB1/Ki-67 was generally high (Table 2 and Figure 1).

Interestingly, stromal cells intermingled with tumor cells were positive for Vimentin, smooth muscle actin and, to a less extent, for CD10.

Table 2 Immunophenotypic characteristics of spindle cell lymphomas

Case 1 Case 2 Case 3 Case 4 Case 5

\begin{tabular}{llllll}
\hline B- and & T-cell associated lymphoid & markers & & & \\
CLA & + & + & + & + & + \\
CD20 & + & + & + & + & + \\
CD79 & + & + & + & + & + \\
CD3 & - & - & - & - & - \\
CD5 & - & - & - & - & -
\end{tabular}

Histogenetic markers of lymphoid B cells reflecting a GC stage of differentiation

$\begin{array}{llllll}\text { CD10 } & - & - & - & - & - \\ \text { BCL6 } & + & + & + & + & +\end{array}$

Histogenetic markers of lymphoid B-cells reflecting late stages of differentiation

MUM1

CD138

Activation and proliferation markers

CD15

CD23

CD30

MIB1

$$
\begin{array}{ccccc}
- & - & - & - & - \\
- & - & + & - & - \\
- & + & - & - & -/+ \\
+(60 \%) & +(70 \%) & +(60 \%) & +(40 \%) & +(40 \%)
\end{array}
$$

Nonlymphoid markers

SMA

Vimentin

S100

CD31

CD34

CD57

Mix (MNF116+CAM 5.2)

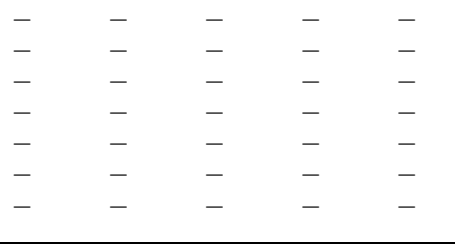

$\mathrm{GC}=$ germinal center; $\mathrm{SMA}=$ smooth muscle actin (clone 1A4).

\section{Molecular Analysis of Clonality}

All five cases were positive for B-cell clonality. Cases 1 and 2 were positive only by FR3 primers while the other three cases were positive also by FR1- and FR2-specific protocols. The corresponding $\mathrm{VH}$ families and the most similar germline genes are reported in Table 3. The rearranged immunoglobulin VH genes were found to be somatically mutated (Table 3). Analysis of T-cell receptor gamma rearrangement scored negative in all cases (not shown).

\section{Molecular Analysis of $t(14 ; 18)$}

All five cases of spindle cell lymphoma scored negative for the $t(14 ; 18)$.

\section{Molecular Analysis of BCL-6 Mutations}

$B C L-6$ mutations were detected in all five cases (Tables 3 and 4). Of the 23 single base-pair substitutions observed in all five cases, 15 were transitions and eight transversions. The 23 nucleotide substitutions showed prevalence of $\mathrm{G}+\mathrm{C}$ over $\mathrm{A}+\mathrm{T}$ with a ratio of 2.8. For each sample, as expected, mutations occurred mostly within RGYW/WRCY motifs $(P<0.001)$ (Table 4). These results confirmed that a physiological somatic hypermutation process was normally active in all five spindle cell lymphomas and hit physiological targets.

\section{Analysis of Viral Infection}

Al five cases of spindle cell lymphoma scored negative for both Kaposi's sarcoma-associated herpesvirus and Epstein-Barr virus.

Table 3 Mutational analysis of IgVH and BCL-6

\begin{tabular}{|c|c|c|c|c|c|}
\hline \multirow[t]{2}{*}{ Patient } & \multicolumn{4}{|c|}{ IgH gene analysis } & \multirow{2}{*}{$\begin{array}{l}\text { BCL- } 6 \\
\text { mutation } \\
\text { position }^{\mathrm{b}}\end{array}$} \\
\hline & $V H$ & $D H$ & $J H$ & $\begin{array}{c}\% \\
\text { Homology }\end{array}$ & \\
\hline 1 & - & D7-27 & $\mathrm{J} 4$ & - & $\begin{array}{l}\text { C686T, } \\
\text { G1003A, } \\
\text { C1084T }\end{array}$ \\
\hline 2 & - & D5-24 & J3 & - & $\begin{array}{l}\text { G638C, G875T, } \\
\text { C1006G, } \\
\text { G1045A, } \\
\text { T1085C }\end{array}$ \\
\hline 3 & $\begin{array}{c}\text { VH3- } \\
73\end{array}$ & D2-15 & J3 & 95.0 & $\begin{array}{l}\text { T557C, G591C, } \\
\text { G648A, G754C, } \\
\text { A956G }\end{array}$ \\
\hline 4 & VH3-7 & D5-24 & J3 & 94.0 & $\begin{array}{l}\text { A448C, A478T, } \\
\text { G479T, G794A, } \\
\text { G855A, C968T }\end{array}$ \\
\hline 5 & $\begin{array}{c}\text { VH3- } \\
30\end{array}$ & D2-2 & J3 & 96.3 & $\begin{array}{l}\text { G734A, } \\
\text { G478A, } \\
\text { G608A, C845T }\end{array}$ \\
\hline
\end{tabular}

Ig = immunoglobulin.

${ }^{\mathrm{a}}$ The $\%$ homology to closest germline IgH V gene. Nomenclature of Ig genes is according to IMGT database.

${ }^{\mathrm{b}}$ Numbering according to GenBank accession no. AY189709. 
Table 4 Features of BCL-6 mutations in spindle cell lymphomas

Patient Mutations/100 bp Deletions and insertions Single bp substitutions Transitions/transversions G+C A+T RGYW (P-value) ${ }^{a}$

\begin{tabular}{lllllll}
\hline 1 & 0.20 & 0 & 3 & $3 / 0$ & 3 & 0 \\
2 & 0.34 & 0 & 5 & $2 / 3$ & $3(<0.001)$ \\
3 & 0.34 & 0 & 5 & $3 / 2$ & 2 & $4(<0.001)$ \\
4 & 0.40 & 0 & 6 & $4 / 3$ & $2(<0.001)$ \\
5 & 0.27 & 0 & 4 & $4 / 0$ & $2(<0.001)$ \\
\hline
\end{tabular}

${ }^{\mathrm{a}}$ The frequency of mutations within RGYW motifs was compared with the frequency of mutations outside RGYW motifs by the $\chi^{2}$ test.

\section{Discussion}

Five new cases of diffuse large B-cell lymphoma with prominent spindle cell features, so-called spindle cell lymphoma, have been analyzed by a multiparameter approach. Morphologically, all five cases exhibited proliferation of spindle cells with a vaguely storiform pattern highly suggestive of spindle cell neoplasms of nonlymphoid origin (Figure 1). In contrast, the results of immunohistochemical analysis indicated that all five cases were hematolymphoid neoplasms of the B-cell lineage. Neoplastic cells from all five cases expressed leukocyte common antigen (CD45) as well as B-cell markers CD20 (Figure 1) and CD79a, but not T-cell markers CD3 or CD5. These findings supported the diagnosis of diffuse large B-cell lymphoma with a prominent spindle cell component for all five patients. These findings confirm that spindle cell lymphoma should be considered together with other morphologically similar neoplasms during differential diagnosis of spindle cell neoplasms of soft tissue, gynecological sites, lymph nodes, and other less frequently affected sites. ${ }^{1,9}$

Spindle cell lymphoma has previously been described as a morphologic variant of diffuse large B-cell lymphoma. ${ }^{1,2,4}$ However, the specific cellular origin from which spindle cell lymphoma develops remains to be clearly defined. The field of B-cell lymphoma histogenesis has progressed rapidly in the past decade due to the increased availability of histogenetic markers of lymphoid cells. ${ }^{11}$ Analysis of the presence or absence of these markers permits classification of $\mathrm{B}$ cells as virgin (pre-germinal center) B cells, germinal center B cells, or postgerminal center B cells. ${ }^{11}$ Genotypic B-cell markers include mutation of immunoglobulin and $B C L-6$ genes. Immunoglobulin gene mutations accumulate during $\mathrm{B}$-cell transit through the germinal center and are maintained after B-cell exit from the germinal center. ${ }^{11,13}$ Recent evidence indicates that normal germinal center B cells also acquire mutations within the noncoding regions of the $B C L-6$ proto-oncogene. ${ }^{14-16}$ Phenotypic B-cell markers include BCL-6 and CD10 proteins, which are expressed after germinal center entry, and MUM1 and CD138/syndecan-1 proteins, which are expressed during the late stages of B-cell maturation. ${ }^{12,17-19,21}$
These genotypic and phenotypic markers permit classification of B-cell lymphomas as: (1) lymphomas devoid of somatic immunoglobulin and BCL-6 gene mutation, which derive from naive pre-germinal center B-cells, (2) lymphomas exhibiting somatic immunoglobulin and BCL- 6 gene mutation as well as BCL-6 and CD10 protein expression, which suggests a germinal center B-cell origin, (3) lymphomas exhibiting somatic immunoglobulin and BCL-6 gene mutation as well as MUM1 and CD138/ syndecan-1 positivity, which may indicate a postgerminal center B-cell origin. ${ }^{18-21}$ The pattern of genotypic and phenotypic markers present in all five spindle lymphoma cases studied suggests that spindle cell lymphoma derives from germinal center B cells and should be classified together with other lymphomas exhibiting somatic immunoglobulin and BCL-6 gene mutation as well as BCL-6 protein expression. The absence of MUM1 expression, which may also occur during the final (centrocyte) stage of intragerminal center B-cell maturation, indicates that spindle cell lymphoma may originate from germinal center B cells undergoing the initial phases of intragerminal center maturation. ${ }^{18}$

All patients in the present study had spindle cell lymphomas that expressed BCL-6, but not CD10. This phenotype was associated with the presence of a primary extranodal origin, normal lactate dehydrogenase levels, and a good response to treatment. Previous studies have similarly demonstrated that B-cell differentiation patterns among diffuse large Bcell lymphoma patients were associated with particular clinicopathological features.. ${ }^{21,25}$ One such study observed that patients with diffuse large Bcell lymphomas expressing BCL-6, but not CD10, more frequently had early stage disease, normal lactate dehydrogenase levels, a primary extranodal origin, and a low or low/intermediate risk international prognostic index than patients with diffuse large B-cell lymphomas expressing both BCL-6 and CD10. ${ }^{25}$

Interestingly, cDNA expression microarrays have proven to be useful for diffuse large B-cell lymphoma prognosis. ${ }^{26-28}$ The germinal center B-cell-like and activated B-cell-like groups were initially identified because their gene expression patterns closely resemble that of normal germinal center Bcells and activated $\mathrm{B}$ cells, respectively. ${ }^{27}$ The 
germinal center B-cell-like group have a significantly better long-term survival than the activated Bcell-like group. BCL-6, CD10, and MUM1 have recently been shown to be expressed differently in the germinal center B-cell-like group in comparison to the activated B-cell-like groups by gene expression array and immunohistochemical analysis. ${ }^{26-29}$ These three markers have been suggested to successfully distinguish germinal center diffuse large B-cell lymphomas from nongerminal center diffuse large B-cell lymphomas. ${ }^{30}$ Both CD10 and BCL-6 have been recognized as germinal center markers, while MUM1 has been found expressed in plasma cells and a subset of cells in the apical light zone of the germinal center, which is consistent with previous observations. ${ }^{18,21,31}$ According to this prognostic model, spindle cell lymphoma could be grouped together with the germinal center-like diffuse large B-cell lymphomas.

In conclusion, the results of this study indicate that spindle cell lymphoma is clinically associated with the presence of primary extranodal disease, normal lactate dehydrogenase levels, and a good response to treatment. Biologically, it is associated with somatic immunoglobulin and $B C L-6$ gene mutations as well as BCL-6 protein expression, and thus neoplastic spindle cells closely reflect B cells residing in the germinal center. With regard to prognosis, spindle cell lymphoma should be grouped together with other germinal center-like diffuse large B-cell lymphomas. ${ }^{26-30}$

\section{Acknowledgements}

We wish to thank Gianni Roncato, Department of Pathology, Istituto Nazionale Tumori, Milano, Italy for his precious help in the preparation of the figures. This work was supported in part by the Italian Alliance Against Cancer (Proteomic Project), Rome, Italy and by the Ministero della Sanita', RF 2003, Rome, Italy

\section{References}

1 Warnke RA, Weiss LM, Chan JKC, et al. Tumors of the lymph nodes and spleen. In: Rosai J, Sobin LH (eds). Atlas of Tumor Pathology. Third Series, Fascicle 14. Armed Forces Institute of Pathology: Washinton, DC, 1994, pp 177-178.

2 Fung CHK, Anter S, Yonan T, et al. Actin-positive spindle cell lymphoma. Arch Pathol Lab Med 1993; 117:1053-1055.

3 Chan JKC, Buchanan R, Fletcher CDM. Sarcomatoid variant of anaplastic large-cell Ki-1 lymphoma. Am J Surg Pathol 1990;14:983-988.

4 Wang J, Sun NC, Nozawa Y, et al. Histological and immunohistochemical characterization of extranodal diffuse large-cell lymphomas with prominent spindle cell features. Histopathology 2001;39:476-481.

5 Dahlin DC, Unni KK. Bone Tumors, General Aspects and Data on 8542 Cases, 4th edn. Charles C Thomas: Springfield, 1986, pp 208-226.
6 Perrone T, Frizzera G, Rosai J. Mediastinal diffuse large-cell lymphoma with sclerosis. A clinicopathologic study of 60 cases. Am J Surg Pathol 1986;10: 176-191.

7 Kahlifa M, Buckstein R, Perez-Ordonez B. Sarcomatoid variant of B-cell lymphoma of the uterine cervix. Int J Gynecol Pathol 2003;22:289-293.

8 Ferrara G, Bevilacqua M, Argenziano G. Cutaneous spindle B-cell lymphoma: a reappraisal. Am J Dermatopathol 2002;24:526-527.

9 Cerroni L, El-Shabrawi-Caelen L, Fink-Puches R, et al. Cutaneous spindle-cell B-cell lymphoma: a morphologic variant of cutaneous large B-cell lymphoma. Am J Dermatopathol 2000;22:299-304.

10 Goodlad JR. Spindle-cell B-cell lymphoma presenting in the skin. Br J Dermatol 2001;145:313-317.

11 Kuppers R, Klein U, Hansmann M-L, et al. Cellular origin of human B-cell lymphomas. N Engl J Med 1999; 341:1520-1529.

12 Carbone A, Gaidano G, Gloghini A, et al. Differential expression of BCL-6, CD138/syndecan-1, and EpsteinBarr virus-encoded latent membrane protein-1 identifies distinct histogenetic subsets of acquired immunodeficiency syndrome-related non-Hodgkin's lymphomas. Blood 1998;91:747-755.

13 Muller-Hermelink HK, Greiner A. Molecular analysis of human immunoglobulin heavy chain variable genes $\left(\operatorname{IgV}_{\mathrm{H}}\right)$ in normal and malignant B cells. Am J Pathol 1998;153:1341-1346.

14 Pasqualucci L, Migliazza A, Fracchiolla $\mathrm{N}$, et al. BCL-6 mutations in normal germinal center B cells: evidence of somatic hypermutation acting outside Ig loci. Proc Natl Acad Sci USA 1998;95: 11816-11821.

15 Shen HM, Peters A, Baron B, et al. Mutation of BCL-6 gene in normal B cells by the process of somatic hypermutation of Ig genes. Science 1998;280: 1750-1752.

16 Capello D, Vitolo U, Pasqualucci L, et al. Distribution and pattern of $B C L-6$ mutations throughout the spectrum of B-cell neoplasia. Blood 2000;95:651-659.

17 Falini B, Fizzotti M, Pucciarini A, et al. A monoclonal antibody (MUM1p) detects expression of the MUM1/ IRF4 protein in a subset of germinal center B cells, plasma cells, and activated T cells. Blood 2000;95: 2084-2092.

18 Gaidano G, Carbone A. MUM1: a step ahead toward the understanding of lymphoma histogenesis. Leukemia 2000;14:563-566.

19 Dogan A, Bagdi E, Munson P, et al. CD10 and BCL-6 expression in paraffin sections of normal lymphoid tissue and B-cell lymphomas. Am J Surg Pathol 2000;24:846-852.

20 Jaffe ES, Harris NL, Stein H, et al (eds). World Health Organization Classification of Tumors, Pathology and Genetics of Tumors of Haematopoietic and Lymphois Tissues. IARC Press: Lyon, 2001.

21 Carbone A, Gloghini A, Larocca LM, et al. Expression profile of MUM1/IRF4, BCL-6, and CD138/syndecan-1 defines novel histogenetic subsets of human immunodeficiency virus-related lymphomas. Blood 2001;97: 744-751.

22 Thériault C, Galoin S, Valmary S, et al. PCR analysis of immunoglobulin heavy chain (IgH) and TcR-g chain gene rearrangements in the diagnosis of lymphoproliferative disorders: results of a study of 525 cases. Mod Pathol 2000;13:1269-1279. 
23 Gaidano G, Pasqualucci L, Capello D, et al. Aberrant somatic hypermutation in multiple subtypes of AIDSassociated non-Hodgkin lymphoma. Blood 2003;102: 1833-1841.

24 Carbone A, Gloghini A, Vaccher E, et al. KSHV/HHV8-positive solid lymphomas. A tissue-based variant of primary effusion lymphoma. J Mol Diagn 2005;7:17-27.

25 Colomo L, Lopez-Guillermo A, Perales $\mathrm{M}$, et al. Clinical impact of the differentiation profile assessed by immunophenotyping in patients with diffuse large B-cell lymphoma. Blood 2003;101:78-84.

26 Alizadeh AA, Eisen MB, Davis RE, et al. Distinct types of diffuse large B-cell lymphoma identified by gene expression profiling. Nature 2000;403:503-511.

27 Rosenwald A, Wright G, Chan WC, et al. The use of molecular profiling to predict survival after chemotherapy for diffuse large-B-cell lymphoma. N Engl J Med 2002;346:1937-1947.
28 Wright G, Tan B, Rosenwald A, et al. A gene expression-based method to diagnose clinically distinct subgroups of diffuse large B cell lymphoma. Proc Natl Acad Sci USA 2003;100:9991-9996.

29 Chang CC, McClintock S, Cleveland RP, et al. Immunohistochemical expression patterns of germinal center anc activation B-cell markers correlate with prognosis in diffuse large B-cell lymphoma. Am J Surg Pathol 2004;28:464-470.

30 Hans CP, Weisenburger DD, Greiner TC, et al. Confirmation of the molecular classification of diffuse large B-cell lymphoma by immunohistochemistry using a tissue microarray. Blood 2003;103:275-282.

31 Carbone A, Gloghini A, Cozzi MR, et al. Expression of MUM1/IRF4 selectively clusters with primary effusion lymphoma among lymphomatous effusions. Implications for disease histogenesis and pathogenesis. Br J Haematol 2000;111:247-257. 